\title{
Role of Judicial Specialization on Improving the Organizational Performance within Judicial Institutions in the United Arab Emirates
}

\author{
Mohamad Alhamad, Mohammed Nusari, Ali Ameen, Valliappan Raju, Amiya Bhumic
}

\begin{abstract}
In the quest to improve performance, attention has been directed at job specialization. Public organizations in UAE are the focus of this paper, specifically the judicial public organization where judicial specialization is applied. The data was collected from 533 employees analyzed using structural equation modeling via software SmartPLS 3.0. The study examines the judicial specialization's effect on organizational performance. The research will describe relationships among the different constructs. Our efforts have improved our understanding of the role of specialization.
\end{abstract}

Keywords: Judicial specialization; organizational performance; United Arab Emirates

\section{INTRODUCTION}

$S_{\text {pecialization states that organizations and individuals }}$ concentrating on the limited range of tasks which best suit their skills and abilities. This specialization entails employees to avoid undertaking other tasks which they may not be skillful at, assigning those jobs to other employees who are better prepared for them. In the current context, the public sector of the UAE has changed in scope over the last few years and continues to implement changes in a manner that is much is similar to the private sector in contemporary times. Turkyilmaz, Akman, Özkan, \& Pastuszak (2011) [1] mention that the UAE public sector seeks to offer customer-centric services and is experiencing an ongoing change in various sectors. As a result of this pressure to change, the public-sector organizations have shown an increased interest in focusing on job specialization that will help achieve results in this regard.

Siddique (2012) [2] stated that UAE has been experiencing high economic growth as compared to other Middle Eastern countries, especially in the fields of tourism, trade, and agriculture, in which the organizations of UAE have extended their business activities [2]. Moreover, the UAE government vows to enhance its performance according to UAE vision 2021 with leadership being at the core of the strategy [3].

Revised Manuscript Received on September 25, 2019

Mohamad Alhamad, Faculty of Business and Accountancy, Lincoln University College, Selangor, Malaysia

Mohammed Nusari, Faculty of Business and Accountancy, Lincoln University College, Selangor, Malaysia

Ali Ameen, Faculty of Business and Accountancy, Lincoln University College, Selangor, Malaysia

Valliappan Raju, Faculty of Business and Accountancy, Lincoln University College, Selangor, Malaysia

Amiya Bhumic, Faculty of Business and Accountancy, Lincoln University College, Selangor, Malaysia

The current research aims at evaluating the effect of judicial specialization on the performance of public organization in the UAE.

\section{LITERATURE REVIEW}

\section{A. Organizational Performance (OP)}

OP is one of the crucial variables in the field of management [4]. It is a standard measure related to environmental responsibility, such as regulatory compliance, cycle time, waste reduction, productivity, efficiency and effectiveness. It is the researchers' eventual dependent variable who are engaged in managerial studies. This wide variable is crucial in allowing managers and researchers to assess organizations over time and match them to rivals [5]. In conclusion, OP is a relevant tool for evaluation of organizational principle, their environments, and actions. This position is revealed in the persistent use of OP as a dependent variable in the study [5].

\section{B. Judicial Specialization (JS)}

The idea of job specialization includes a process to break down any task to its minimum level and crafting jobs based on each part. This generates expertise, specialization, and improved quality. The design of job specialization in organizations is regularly viewed where an employee focuses on one precise task and ability throughout the whole job assignment. The task normally recurrences all along. Due to job specialization facilitates significant expertise growth in a specific job, the speed of execution and learning happen faster. Theoretically, this method decreases the costs of quality control and enhances efficiency [6]. In the current context of judicial public institutions in UAE, implementing the specialization method in creating special courts and assigning specific juries is seen as a way to enhance the performance of these public institutions. Consequently, the following hypothesis is proposed:

H1. Judicial specialization significantly has a positive impact on organizational performance.

Figure 1 shows the proposed study model which contain one independent variable (judicial specialization) and one dependent variable (organizational performance).

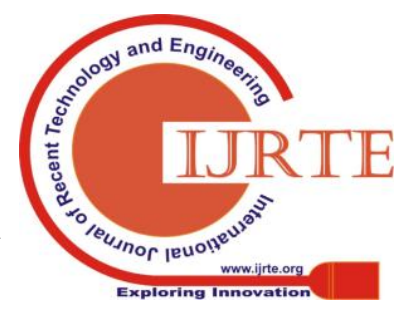


The Role of Judicial Specialization on Improving the Organizational Performance within Judicial Institutions in the United Arab Emirates

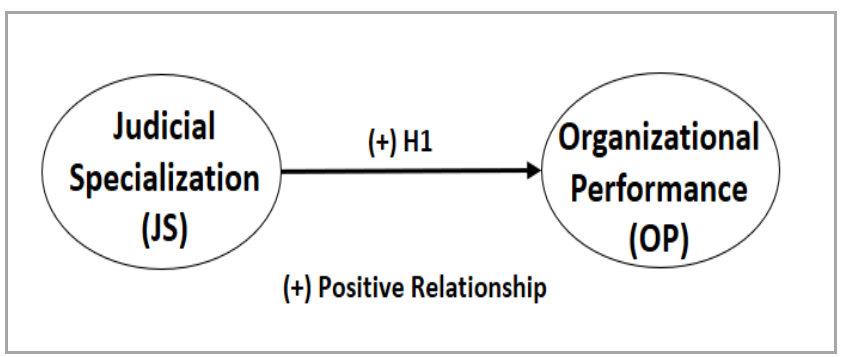

Fig 1: The proposed model

\section{RESEARCH DESIGN AND METHODOLOGY}

\section{A. Development of Instrument and Data collection}

The creation of a tool for this research involved a questionnaire of 16 questions, and on the basis of the literature on human resource management, the research employed a multi-item Likert scale [7]. The parameters were evaluated using a Likert scale recommended in the earlier studies [8]. The information was gathered by delivering a self-managed questionnaire 'in-person' between November 2018 and December 2018 to public organizations in Abu Dhabi in UAE. The number of the distributed questionnaires was 650 , which 533 responses were considered suitable for the analysis. According to Tabachnick \& Fidell (2012) [9] and Krejcie \& Morgan (1970) [10], the sample size was seen as sufficient.

\section{Data Analysis and Results}

Partial Least Squares (PLS) was utilized to test the research model, using the SmartPLS 3.0 software. A two-stage analytical method [11] was used which comprising (i) measurement model assessment (validity and reliability) and (ii) structural model assessment (testing the hypothesized relationships).

\section{A.Descriptive analysis}

Judicial specialization scores the highest with mean 3.63 out of 5.0, with a standard deviation of 1.155. Organizational performance scores the lowest with mean 3.51 out of 5.0, with a standard deviation of 1.237, as Table 1 shows.

\section{B. Measurement Model Assessment}

Construct reliability as well as validity (comprising discriminant and convergent validity) were used to examine the measurement model. The particular alpha coefficients of Cronbach were tested to determine the reliability of every core parameter in the measurement model (construct reliability). The quantities of all the unique alpha coefficients of Cronbach in this research exceeded 0.7 [12]. Moreover, for inspecting construct reliability, all the CR (composite reality) values went beyond 0.7 except JS1 and OP11 that were deleted $[13,14]$. Thus, as Table 1 shows, construct reliability have been fulfilled as Cronbach's CR and alpha were rather error-free for all the parameters.

Table 1: Measurement assessment results

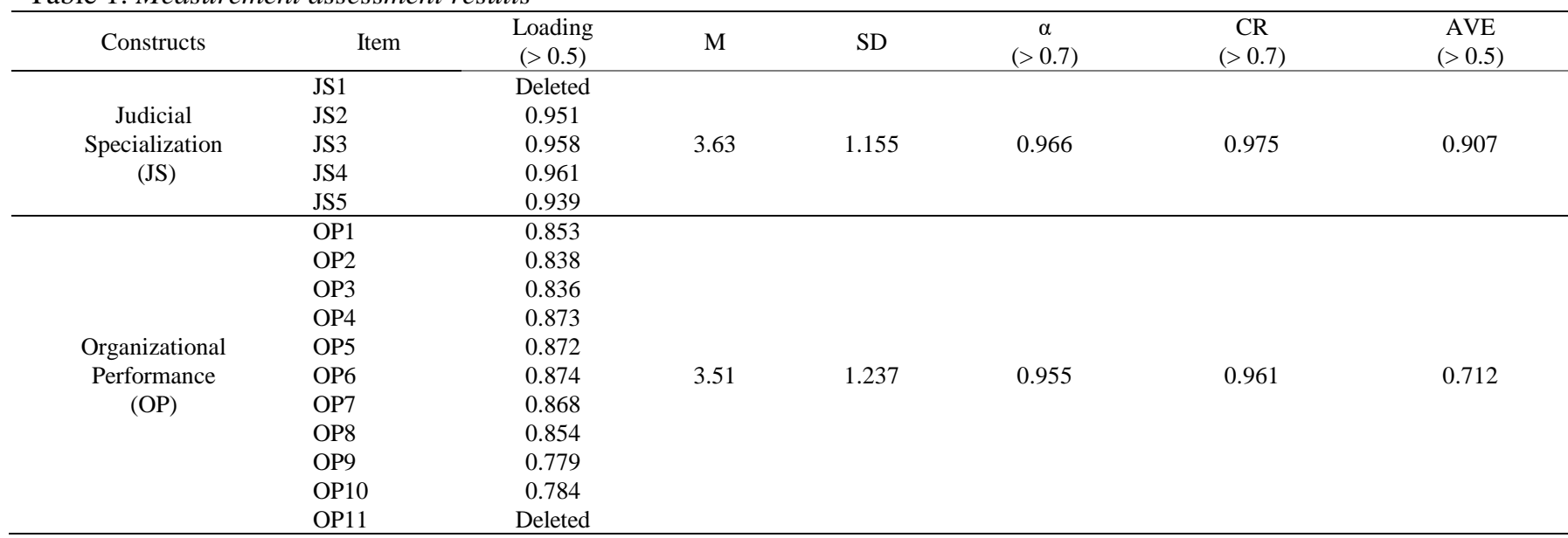

Note: $\mathrm{M}=$ Mean; $\mathrm{CR}=$ Composite Reliability; $\alpha=$ Cronbach's alpha; AVE = Average Variance Extracted; $\mathrm{SD}=\mathrm{Standard}$ Deviation.

Key: JS: Judicial Specialization, OP: Organizational Performance

The degree to which the articles distinguish among concepts or measure different constructs is demonstrated by discriminant validity. Fornell-Larcker was employed to analyse the measurement model's discriminant validity. Table 2 shows the outcomes for discriminant validity by employing the Fornell-Larcker condition. It was discovered that the AVEs' square root on the diagonals (displayed in bold) is bigger than the correlations among constructs (corresponding row as well as column values), suggesting a strong association between the concepts and their respective markers in comparison to the other concepts in the model $[15,16]$. According to Hair et al. (2017) [17], this indicates good discriminant validity. Furthermore, the exogenous constructs have a correlation of less than 0.85 [18]. Therefore, all constructs had their discriminant validity fulfilled satisfactorily. 
Table 2: Results of discriminant validity by Fornell-Larcker criterion

\begin{tabular}{l|cccccccccc}
\hline & $A A T$ & $A W$ & $I S Q$ & $L E A$ & $P R O$ & $P U$ & $R P A$ & $S I$ & $S Q$ & $T R$ \\
\hline AAT & $\mathbf{0 . 8 6 4}$ & & & & & & & & & \\
AW & 0.525 & $\mathbf{0 . 8 8 0}$ & & & & & & & & \\
ISQ & 0.758 & 0.442 & $\mathbf{0 . 8 6 2}$ & & & & & & & \\
LEA & 0.787 & 0.487 & 0.750 & $\mathbf{0 . 8 6 3}$ & & & & & & \\
PRO & 0.756 & 0.514 & 0.656 & 0.696 & $\mathbf{0 . 8 6 2}$ & & & & & \\
PU & 0.556 & 0.728 & 0.502 & 0.559 & 0.539 & $\mathbf{0 . 8 5 8}$ & & & & \\
RPA & 0.783 & 0.474 & 0.774 & 0.749 & 0.720 & 0.570 & $\mathbf{0 . 8 5 7}$ & & & \\
SI & 0.514 & 0.730 & 0.438 & 0.488 & 0.491 & 0.738 & 0.489 & $\mathbf{0 . 8 9 2}$ & & \\
SQ & 0.540 & 0.791 & 0.486 & 0.504 & 0.491 & 0.785 & 0.488 & 0.791 & $\mathbf{0 . 9 1 4}$ & \\
TR & 0.520 & 0.765 & 0.441 & 0.453 & 0.485 & 0.738 & 0.477 & 0.703 & 0.802 & $\mathbf{0 . 9 0 2}$ \\
\hline
\end{tabular}

Note: $\mathrm{M}=$ Mean; $\mathrm{CR}=$ Composite Reliability; $\alpha=$ Cronbach's alpha; $\mathrm{AVE}=$ Average Variance Extracted; $\mathrm{SD}=\mathrm{Standard}$ Deviation.

Key: JS: Judicial Specialization, OP: Organizational Performance.

The degree to which the articles distinguish among concepts or measure different constructs is demonstrated by discriminant validity. Cross-loadings as well as Fornell-Larcker were employed to analyse the measurement model's discriminant validity. Generally, cross-loadings are employed as the initial step in examining discriminant

validity of the indicators [17]. In this research, the indicators outer loadings on a construct went beyond all the cross-loadings with other parameters, and thus the cross-loading condition had met the requirements (refer to Table 2).

Table 2: Discriminant validity Results

\begin{tabular}{c|cc}
\hline & $J S$ & $O P$ \\
\hline JS2 & $\mathbf{0 . 9 5 1}$ & 0.365 \\
JS3 & $\mathbf{0 . 9 5 8}$ & 0.352 \\
JS4 & $\mathbf{0 . 9 6 1}$ & 0.358 \\
JS5 & $\mathbf{0 . 9 3 9}$ & 0.305 \\
OP1 & 0.328 & $\mathbf{0 . 8 5 3}$ \\
OP2 & 0.305 & $\mathbf{0 . 8 3 8}$ \\
OP3 & 0.282 & $\mathbf{0 . 8 3 6}$ \\
OP4 & 0.349 & $\mathbf{0 . 8 7 3}$ \\
OP5 & 0.301 & $\mathbf{0 . 8 7 2}$ \\
OP6 & 0.299 & $\mathbf{0 . 8 7 4}$ \\
OP7 & 0.292 & $\mathbf{0 . 8 6 8}$ \\
OP8 & 0.295 & $\mathbf{0 . 8 5 4}$ \\
OP9 & 0.286 & $\mathbf{0 . 7 7 9}$ \\
OP10 & 0.319 & $\mathbf{0 . 7 8 4}$ \\
\hline
\end{tabular}

Key: JS: Judicial Specialization, OP: Organizational Performance.

Table 3 shows the outcomes for discriminant validity by employing the Fornell-Larcker condition. It was discovered that the AVEs' square root on the diagonals (displayed in bold) is bigger than the correlations among constructs (corresponding row as well as column values), suggesting a strong association between the concepts and their respective markers in comparison to the other concepts in the model $[15,16]$. According to Hair et al. (2017) [17], this indicates good discriminant validity. Furthermore, the exogenous constructs have a correlation of less than 0.85 [18]. Therefore, all constructs had their discriminant validity fulfilled satisfactorily.

Table 3: Results of discriminant validity by Fornell-Larcker criterion

\begin{tabular}{c|cc}
\hline & $J S$ & $O P$ \\
\hline JS & $\mathbf{0 . 9 5 2}$ & $\mathbf{0 . 8 4 4}$ \\
OP & 0.364 &
\end{tabular}

Key: JS: Judicial Specialization, OP: Organizational Performance. 


\section{C.Structural Model Assessment}

The structural model can be tested by computing beta $(\beta), R^{2}$, and the corresponding $t$-values via a bootstrapping procedure with a resample of 5,000 [17]

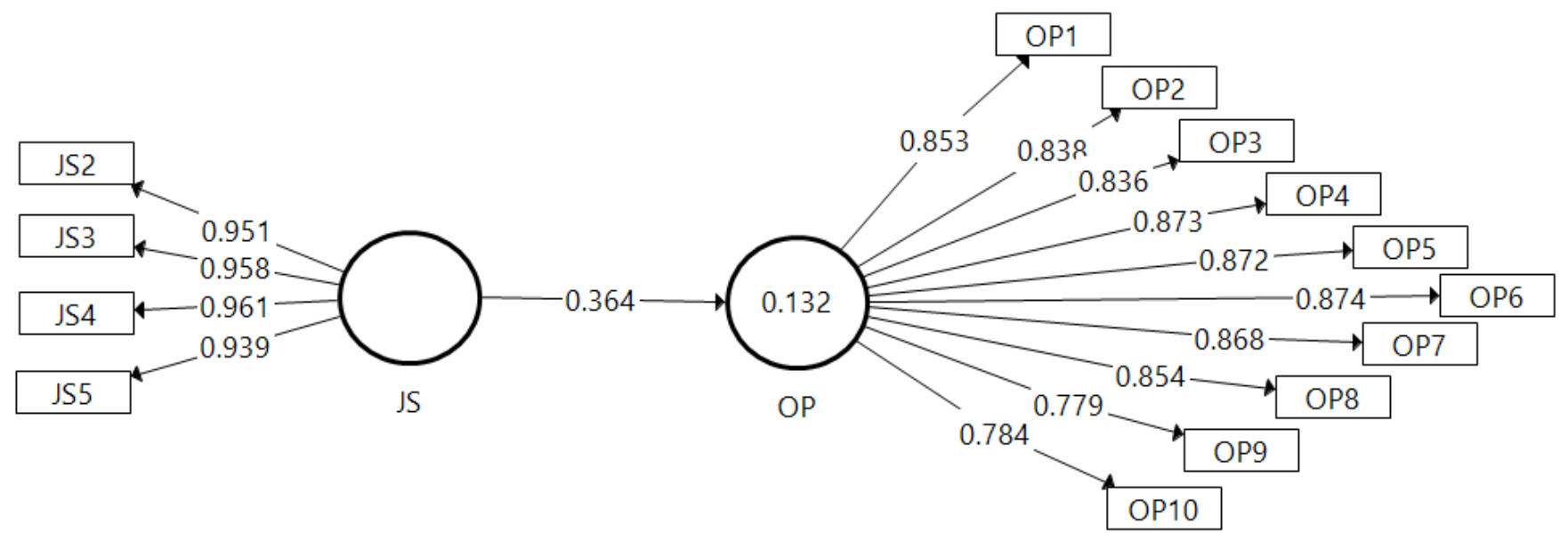

Key: JS: Judicial Specialization, OP: Organizational Performance

Fig 2: PLS algorithm results

Figure 2 and Table 4 depict the structural model assessment, showing the results of the hypothesis tests. Judicial specialization significantly predicts organizational performance. Hence, $\mathrm{H} 1$ is accepted with $(\beta=0.364, \mathrm{t}=9.284, \mathrm{p}<0.001)$.
Thirteen percent of the variance in organizational performance is explained by judicial specialization. The values of $R^{2}$ have an acceptable level of explanatory power, indicating a substantial model [16].

Table 4: Structural assessment results

\begin{tabular}{clllllcc}
\hline \hline Hypothesis & Relationship & Std Beta & Std Error & t-value & p-value & Decision & $\mathrm{R}^{2}$ \\
\hline H1 & JS $\rightarrow$ OP & 0.364 & 0.039 & 9.284 & 0.000 & Supported & 0.13 \\
\hline \hline
\end{tabular}

Key: JS: Judicial Specialization, OP: Organizational Performance

\section{Discussion}

Based on the proposed model, this study improves the understanding of the role played by specialization in public sector organizations. The discussions are further detailed in the following.

The study found that Judicial Specialization positively affect organizational performance among organizations in public sector in UAE, this is supported by previous studies $[19,20]$. It is explained by the fact that The more the Judicial Specialization contributes to reducing the time and effort needed to issue judgments in cases, makes the member of the judiciary more distinguished in his/her work compared to work in various types of cases, helps to expedite the adjudication of cases, and contributes to the quality of judicial decisions.. The more the organization can be industry leader, forward-looking organization, responsive to local and international market needs, experience growth in revenue, market share and profit, improve operating efficiency, achieve and sustain superior performance, achieves a high success rate in new service launched, and continuously produce competitive services.

\section{IMPLICATIONS, LIMITATIONS AND FUTURE DIRECTIONS}

The paper enhances the knowledge base of the performance scheme in UAE and to the job nature in multi-cultural organizational environments. Future research in performance improvement effort can be investigated from other viewpoints to identify other determinants to advance the performance of organizations. Moreover, further studies can be done in terms of identifying the impact of such job diversification in UAE organizations and scale them to global research. This paper has shed some light on the public sector and can be used as a basis to perform other studies of high performing organizations which can be of help to mangers in their quest for excellence. While this research is a first approach and is bound by one public sector organization (judicial organizations), its results are beneficial to other public organizations in different fields [21].

Organizations can utilize the findings of this study to advance their overall performance. For instance by constructing a highly specialized jobs. It is vital for organizations to begin by evaluating their specific needs and identify areas of improvements to reach a satisfying status. In order to inspire certain types of organizational specializations, organizations must focus their attention on the fundamental indices and characteristics for that type of job [22].

\section{CONCLUSION}

Although the United Arab Emirates government institutions are known to be a regional pioneer among its peers performance wise, it is determined to continuously enrich its organizations in public sector performance [23], 
the outcome of this study may be seen as one of the advantages to support that direction. The main aim of this study is to examine the role of judicial specialization in enhancing the performance of organizations in the public sector of the United Arab Emirates. Regardless of numerous limitations to the study, the results have been encouraging, as

\section{APPENDIX}

Appendix A

Instrument for varibles it has managed to throw some lights on a new perspective. This research model tested the impact of judicial specialization on organizational performance. The results stated impact of independent variable on the dependent variable. Varible Measure Source

JS1: Judicial Specialization contributes to reducing the time and effort spent to issue judgments and the speed of adjudication in cases.

Judicial Specialization JS2: Judicial specialization makes the member of the judiciary more distinguished in his work compared to work in various types of cases.

JS3: The establishment of specialized courts helps to expedite the adjudication of cases.

JS4: The appropriate years of experience that qualify a member of the judiciary to a specialization must not be less than 5 years.

JS5: Judicial specialization contributes to the quality of judicial decisions.

OP1: Our organization industry leader.

OP2: Our organization is a forward-looking organization.

OP3: Our organization is quickly responsive to local and international market needs.

OP4: Our revenue growth is improving.

Organizational OP5: Our market share is improving.

Performance OP6: Our profit growth is improving.

(OP) OP7: Our organization is improving operating efficiency.

OP8: Our organization is always able to achieve and sustain superior performance.

OP9: Our organization practices 'On Time Delivery' of its services to the customers.

OP10: Our organization achieves a high success rate in new service launched.

OP11: Our organization is continuously produce competitive services.

\section{REFERENCES}

1. 1. A. Turkyilmaz, G. Akman, C. Özkan \& Z. Pastuszak, (2011). Empirical Study of Public Sector Employee Loyalty and Satisfaction. Industrial Management and Data Systems, 111

2. 2. M. Siddique (2012). Knowledge management initiatives in the United Arab Emirates: a baseline study. Journal of Knowledge Management, 16(5), pp. 702-723.

3. 3. M. Mathias, (2017). Public leadership in the United Arab Emirates: towards a research agenda. International Journal of Public Sector Management, 30(2), pp. 154-169.

4. 4. C. Gavrea, L. Ilies \& R. Stegerean (2011). Determinants of organizational performance: The case of Romania. Management \& Marketing, 6(2), pp. 285-300.

5. 5. P. J. Richard, T. M. Devinney, G. S. Yip \& G. Johnson, (2009). Measuring Organizational Performance: Towards Methodological Best Practice. Journal of Management, 35(3), pp. 718-804.

6. 6. J. Lee \& Q. P. He (2019). Understanding the effect of specialization on hospital performance through knowledge-guided machine learning. Computers \& Chemical Engineering, 125, pp. 490-498.

7. 7. B. C. Lee, J. O. Yoon \& I. Lee (2009). Learners' acceptance of e-learning in South Korea: Theories and results. Computers and Education, 53(4), pp. 1320-1329.

8. 8. O. Isaac, Z. Abdullah, T. Ramayah \& A. M. Mutahar, (2017a). Examining the Relationship between Overall Quality, User Satisfaction and Internet Usage: An Integrated Individual, Technological, Organizaional and Social Perspective. Asian Journal of Information Technology, 16(1), pp. 100-124.

9. 9. B. G. Tabachnick \& L. S. Fidell (2012). Using Multivariate Statistics (6th ed.). New York: Pearson.

10. 10. R. V Krejcie \& D. W. Morgan (1970). Determining Sample Size for Research Activities Robert. Educational and Psychological Measurement, 38(1), pp. 607-610.

11. 11. J. C. Anderson \& Gerbing D. W. (1988). Structural equation modeling in practice: A review and recommended two-step approach. Psychological Bulletin, 103(3), pp. 411-423.

12. 12. V. R. Kannana \& K. C. Tan (2005). Just in time, total quality management, and supply chain management: understanding their linkages and impact on business performance. Omega: The International Journal of Management Science, 33(2), pp. 153-162.
13. 13. C. E. Werts, R. L. Linn \& K. G. Jöreskog (1974). Intraclass reliability estimates: Testing structural assumptions. Educational and Psychological Measurement, 34(1), pp. 25-33.

14. 14. R. B. Kline, (2010). Principles and practice of structural equation modeling (3rd ed.). New York: The Guilford Press.

15. 15. C. Fornell \& D. F. Larcker, (1981). Evaluating structural equation models with unobservable variables and measurement error. Journal of Marketing Research, 18(1), pp. 39-50.

16. 16. W. W. Chin (1998). Issues and opinion on structural equation modeling. MIS Quarterly, 22(1), pp. 7-16.

17. 17. J. F. Hair, G. T. M. Hult, C. Ringle \& M. Sarstedt, (2017). A Primer on Partial Least Squares Structural Equation Modeling (PLS-SEM) (2nd ed.). London: Thousand Oaks: SAGE.

18. 18. Z. Awang (2014). Structural Equation Modeling Using AMOS Shah Alam.Malaysia: Penerbit Universiti Teknologi MARA.

19. 19. V. Capkun, M. Messner, C. Rissbacher, V. Capkun \& M. Messner, (2012). Service specialization and operational performance in hospitals. International Journal of Operations \& Production Management, 32(4), pp. 468-495.

20. 20. G. M. Cortes \& A. Salvatori (2019). Delving into the demand side Changes in workplace specialization and job polarization. Labour Economics, 57, pp. 164-176.

21. 21. F. Lasrado \& C. Uzbeck, (2017). The excellence quest: a study of business excellence award-winning organizations in UAE. Benchmarking, 24(3), pp. 716-734.

22. 22. R. Kassem, M. Ajmal, A. Gunasekaran \& P. Helo (2018). Assessing the impact of organizational culture on achieving business excellence with a moderating role of ICT. Benchmarking: An International Journal, BIJ-03-2018-0068.

23. 23. Global Innovation Index. (2016). Government institutions effectiveness: Yemen versus Arab countries: Rank among 143 countries, Cornell University, INSEAD, and the World Intellectual Property Organization (WIPO)

24. 24. M. Pinar \& T. Girard (2008). Investigating the Impact of Organizational Excellence and Leadership on Achieving Business Performance: An Exploratory Study of Turkish Firms. Advanced Management Journal, 73(1), pp. 29-45. 